OPEN ACCESS

Edited by:

Zhiliang $\mathrm{Hu}$,

Nanjing Second Hospital, China

Reviewed by:

Peng Huang,

Nanjing Medical University, China

Jorge Quarleri,

Consejo Nacional de Investigaciones

Cientificas y Técnicas

(CONICET), Argentina

*Correspondence:

María Angeles Jiménez-Sousa

jimenezsousa@isciii.es;

majimenezsousa@yahoo.es

tThese authors have contributed equally to this work

Specialty section:

This article was submitted to Infectious Diseases - Surveillance,

Prevention and Treatment,

a section of the journal

Frontiers in Medicine

Received: 08 October 2020 Accepted: 04 January 2021

Published: 01 February 2021

Citation:

Medrano LM, Berenguer J,

Salgüero S, González-García J,

Díez C, Hontañón V

Garcia-Broncano P

Ibañez-Samaniego L, Bellón JM,

Jiménez-Sousa MA and Resino S

(2021) Successful HCV Therapy Reduces Liver Disease Severity and

Inflammation Biomarkers in

HIV/HCV-Coinfected Patients With Advanced Cirrhosis: A Cohort Study.

Front. Med. 8:615342.

doi: 10.3389/fmed.2021.615342

\section{Successful HCV Therapy Reduces Liver Disease Severity and Inflammation Biomarkers in HIV/HCV-Coinfected Patients With Advanced Cirrhosis: A Cohort Study}

\author{
Luz Maria Medrano ${ }^{1}$, Juan Berenguer ${ }^{2,3}$, Sergio Salgüero ${ }^{1,4}$, Juan González-García ${ }^{5}$, \\ Cristina Díez ${ }^{2,3}$, Víctor Hontañón ${ }^{5}$, Pilar Garcia-Broncano ${ }^{1,6}$, Luis Ibañez-Samaniego ${ }^{7}$, \\ José M. Bellón ${ }^{8}$, María Angeles Jiménez-Sousa ${ }^{1 * t}$ and Salvador Resino ${ }^{1 \dagger}$ \\ 1 Unidad de Infección Viral e Inmunidad, Centro Nacional de Microbiología, Instituto de Salud Carlos III, Madrid, Spain, \\ 2 Unidad de Enfermedades Infecciosas/VIH, Hospital General Universitario "Gregorio Marañón", Madrid, Spain, ${ }^{3}$ Instituto de \\ Investigación Sanitaria del Gregorio Marañón, Madrid, Spain, " Unidad de Análisis Clínicos, Hospital Universitario Fundación \\ Alcorcón, Alcorcón, Spain, ${ }^{5}$ Unidad de VIH, Servicio de Medicina Interna, Hospital Universitario "La Paz"/IdiPAZ, Madrid, \\ Spain, ${ }^{6}$ Ragon Institute of MGH, MIT and Harvard, Cambridge, MA, United States, ${ }^{7}$ Servicio de Aparato Digestivo, Hospital \\ General Universitario "Gregorio Marañón", Madrid, Spain, ${ }^{8}$ Fundación para la Investigación Biomédica, Hospital General \\ Universitario Gregorio Marañón, Instituto de Investigación Sanitaria Gregorio Marañón (IISGM), Madrid, Spain
}

Background: Eradication of hepatitis C virus ( $\mathrm{HCV}$ ) promotes an improvement in liver disease and the deactivation of the immune system. Here, we aimed to evaluate the changes in liver disease scores and plasma biomarkers following HCV clearance with direct-acting antivirals (DAAs) in HIV-infected patients with advanced HCV-related cirrhosis.

Methods: We performed an observational study of 50 patients with advanced cirrhosis who received DAAs therapy. Variables were assessed at baseline and 48 weeks after HCV treatment completion. Epidemiological and clinical data were collected through an online form. Liver stiffness measurement (LSM), hepatic venous pressure gradient (HVPG), and Child-Pugh-Turcotte (CTP) were evaluated by physicians. Plasma biomarkers were measured by multiplex immunoassay.

Results: We found significant decreases in severity scores of liver disease [LSM ( $q$-value $<0.001)$, HVPG $(q$-value $=0.011)$, and CTP $(q$-value $=0.045)]$ and plasma biomarkers [LBP ( $q$-value $<0.001), \mathrm{IP}-10$ ( $q$-value $<0.001)$, IL-8 $(q$-value $<0.001)$, IL-18 ( $q$-value $<0.001$ ), IL-1RA ( $q$-value $=0.013)$, OPG $(q$-value $<0.001)$, sVCAM-1 ( $q$-value $<0.001)$, sICAM-1 ( $q$-value $<0.001)$, PAl-1 ( $q$-value $=0.001)$, and VEGF-A $(q$-value $=0.006)]$. We also found a significant direct association between the change in LSM values and the change in values of LBP ( $q$-value $<0.001)$, IP-10 ( $q$-value $<0.001$ ), MCP-1 ( $q$-value $=0.008)$, IL-8 ( $q$-value $<0.001)$, IL-18 ( $q$-value $<0.001)$, OPG ( $q$-value $=0.004$ ), sVCAM-1 ( $q$-value < 0.001), sICAM-1 ( $q$-value < 0.001), and PAI-1 ( $q$-value $=$ 0.002). For CTP values, we found significant positive associations with IP-10 ( $q$-value $=$ 0.010), IL-6 ( $q$-value $=0.010)$, IL-1RA ( $q$-value $=0.033$ ), and sICAM-1 $(q$-value $=0.010)$. 
Conclusion: The HCV eradication with all-oral DAAs in HIV/HCV-coinfected patients with advanced cirrhosis promoted an improvement in the severity of advanced cirrhosis and plasma biomarkers (inflammation, coagulopathy, and angiogenesis). The decrease in plasma biomarkers was mainly related to the reduction in LSM values.

Keywords: chronic hepatitis $\mathrm{C}(\mathrm{CHC})$, direct-acting antiviral (DAA) therapy, HIV/HCV co-infected patients, cirrhosis, inflammation, coagulopathy, angiogenesis

\section{INTRODUCTION}

Hepatitis $\mathrm{C}$ virus (HCV) infection triggers an immune response against the viral infection, but it also promotes chronic inflammation, immune activation, and immune dysfunction that accelerate the development of liver fibrosis and other comorbidities $(1,2)$. Additionally, in advanced stages, cirrhosis-associated immune dysfunction (CAID) usually appears, characterized by higher inflammation levels, immune activation, and immunosuppression in the liver and peripheral blood (3). The extent of CAID is directly related to liver disease severity and plays a decisive role in its progression to hepatic decompensation (3). Patients with hepatic decompensation may develop complications related to portal hypertension, such as ascites, jaundice, variceal bleeding, or hepatic encephalopathy, decreasing quality of life and survival rates (4). The direct-acting antiviral agents (DAAs) against $\mathrm{HCV}$ have increased sustained virologic response (SVR) rates in patients with advanced HCV-related cirrhosis, which improves the quality of life and reduce morbidity from cirrhosis (5). Additionally, significant decreases in liver disease scores [liver stiffness measurement (LSM), hepatic venous pressure gradient (HVPG) or Child-PughTurcotte (CTP)] (6-14) and plasma biomarkers related to inflammation and immune activation (15-20) have been described in HCV-monoinfected patients after SVR with all-oral DAAs.

The human immunodeficiency virus (HIV) infection accelerates the course of chronic hepatitis $\mathrm{C}(\mathrm{CHC})$, resulting in higher rates of cirrhosis, end-stage liver disease, and death than HCV-monoinfected patients (21). HIV infection increases a series of negative factors such as HCV replication, hepatic inflammation, hepatocyte apoptosis, and microbial

\footnotetext{
Abbreviations: HCV, hepatitis C virus; CHC, chronic hepatitis C; CAID, cirrhosis-associated immune dysfunction; DAAs, direct-acting antiviral agents; SVR, Sustained virologic response; LSM, liver stiffness measurement; HVPG, hepatic liver pressure gradient; CTP, Child-Pugh-Turcotte; HIV, human immunodeficiency virus; ART, combination antiretroviral therapy; $\mathrm{kPa}$, kilopascals; mmHG, millimeter of mercury; sCD14, soluble CD14; LPS, lipopolysaccharide; FABP2, fatty acid-binding protein 2; LBP, lipopolysaccharide binding protein; IP-10, IFN- $\gamma$-inducible protein 10; MCP1, monocyte chemoattractant protein-1; IL, Interleukin; TNF- $\alpha$, tumor necrosis factor alpha; IL-1RA, interleukin-1 receptor antagonist; sRANKL, soluble receptor activator of nuclear factor-kappa B ligand; OPG, osteoprotegerin; sVCAM1, soluble vascular cell adhesion molecule 1; sICAM1, soluble intercellular cell adhesion molecule 1; sTNFR1, soluble tumor necrosis factor receptor 1; PAI-1, plasminogen activator inhibitor-1; VEGF-A, vascular endothelial growth factor A; sVEGF-R1, soluble receptor 1 for vascular endothelial growth factor; GLMM, Generalized Linear Mixed Models; IFN, interferon.
}

translocation, while it also leads to a deterioration of the specific immune responses against $\operatorname{HCV}(22,23)$. Antiretroviral therapy (ART) delays the fibrosis progression and reduces clinical complications, but despite suppressive ART, HIV/HCVcoinfected patients still have abnormally high levels of plasma biomarkers related to bacterial translocation, immune activation, inflammation, and coagulation (23), which are related to higher morbidity and mortality (24). Similarly, DAA treatments against HCV infection also achieve elevated SVR rates $(25,26)$ and delay $\mathrm{CHC}$ progression in $\mathrm{HIV} / \mathrm{HCV}$-coinfected patients $(27,28)$. Several reports have shown a significant decrease in plasma biomarkers related to inflammation and immune activation after SVR with all-oral DAAs in HIV/HCV-coinfected patients (18, 29-33). However, DAA therapy alone does not entirely block uncontrolled inflammation and liver injury, particularly with advanced liver disease (34). Thus, some cirrhotic patients who achieve SVR with DAAs remain at risk of cirrhosis progression and developing hepatocellular carcinoma (1).

In this study, we aimed to evaluate the changes in liver disease scores and plasma biomarkers following HCV clearance with DAAs in HIV-infected patients with advanced HCVrelated cirrhosis.

\section{PATIENTS AND METHODS}

\section{Patients}

We carried out a multicenter observational study (repeated measures design) in $50 \mathrm{HIV}$-infected patients with advanced HCV-related cirrhosis who started anti-HCV therapy with all-oral DAAs. Patients were recruited at four tertiary referral hospitals in Madrid (Spain) between January 2015 and June 2016 (ESCORIAL study; see Appendix). The study was approved by the Ethics Committee of the Instituto de Salud Carlos III (CEI PI 41_2014) and was conducted according to the Declaration of Helsinki. All participants gave their written consent before enrollment.

The inclusion criteria were: (1) active HCV infection at baseline defined by detectable plasma HCV-RNA; (2) advanced cirrhosis [LSM $\geq 25 \mathrm{kPa}$, or HVPG $\geq 10 \mathrm{mmHg}$, or CTP $\geq$ 7 , or prior history of liver decompensation (ascites, varices, bleeding esophageal, hepatic encephalopathy)]; (3) starting antiHCV therapy with all-oral DAAs (without interferon (IFN) or ribavirin) and achieving an SVR defined as an undetectable HCV-RNA load 12 weeks after the finalization of antiHCV treatment. 
TABLE 1 | Summary of characteristics of HIV-infected patients with advanced HCV-related cirrhosis at baseline.

\begin{tabular}{|c|c|}
\hline Characteristics & Data \\
\hline No. & 50 \\
\hline Gender (male) & $39(78 \%)$ \\
\hline Age (years) & $52.2(48.8 ; 54.1)$ \\
\hline \multicolumn{2}{|l|}{ Smoker } \\
\hline Never & $6(12.2 \%)$ \\
\hline Previously ( $\geq 6$ months) & $12(24.5 \%)$ \\
\hline Currently & $31(63.3 \%)$ \\
\hline \multicolumn{2}{|l|}{ Alcohol intake } \\
\hline Never & $21(42 \%)$ \\
\hline Previously ( $\geq 6$ months) & $24(48 \%)$ \\
\hline Currently & $5(10 \%)$ \\
\hline \multicolumn{2}{|l|}{ IVDU } \\
\hline Never & $12(24 \%)$ \\
\hline Previously ( $\geq 6$ months) & $38(76 \%)$ \\
\hline Currently & $0(0 \%)$ \\
\hline \multicolumn{2}{|l|}{ Treatments } \\
\hline Statins & $8(16 \%)$ \\
\hline Previous IFN $\alpha$ therapy & $23(46 \%)$ \\
\hline \multicolumn{2}{|l|}{ DAAs regimens } \\
\hline Sofosbuvir + Ledipasvir & $20(40 \%)$ \\
\hline Sofosbuvir + Daclatasvir & $14(28 \%)$ \\
\hline Sofosbuvir + Daclatasvir + Simeprevir & $3(6 \%)$ \\
\hline Sofosbuvir + Simeprevir & $10(20 \%)$ \\
\hline Ombitasvir + Paritaprevir + Ritonavir + Dasabuvir & $3(6 \%)$ \\
\hline \multicolumn{2}{|l|}{ Antiretroviral therapy } \\
\hline NRTI + NNRTI-based & $7(14.3 \%)$ \\
\hline NRTI + II-based & $24(49 \%)$ \\
\hline $\mathrm{NRTI}+\mathrm{Pl}$-based & $6(12.2 \%)$ \\
\hline $\mathrm{PI}+\|$ + others-based & $4(8.2 \%)$ \\
\hline Others & $8(16.3 \%)$ \\
\hline \multicolumn{2}{|l|}{ HIV markers } \\
\hline Prior AIDS & $18(36 \%)$ \\
\hline Nadir CD4+ T-cells (cells/mm³) & $114.7(70 ; 182)$ \\
\hline Nadir $\mathrm{CD}^{+}<200$ cells $/ \mathrm{mm}^{3}$ & $35(76.1 \%)$ \\
\hline $\mathrm{CD}^{+}{ }^{+} \mathrm{T}$-cells (cells $/ \mathrm{mm}^{3}$ ) & $439(234 ; 721)$ \\
\hline $\mathrm{CD} 4+<500$ cells $/ \mathrm{mm}^{3}$ & $30(60 \%)$ \\
\hline \multicolumn{2}{|l|}{ HCV markers } \\
\hline \multicolumn{2}{|l|}{ HCV genotype } \\
\hline 1 & $32(65.3 \%)$ \\
\hline 3 & $7(14.3 \%)$ \\
\hline 4 & $10(20.4 \%)$ \\
\hline $\log _{10}$ HCV-RNA (IU/mL) & $6.2(5.7 ; 6.7)$ \\
\hline HCV-RNA $\geq 850.000 \mathrm{IU} / \mathrm{mL}$ & $33(66 \%)$ \\
\hline \multicolumn{2}{|l|}{ Liver disease markers } \\
\hline LSM (kPa) & $31.6(23.4 ; 40.7)$ \\
\hline$<25 \mathrm{kPa}$ & $16(26.7 \%)$ \\
\hline $25-40 \mathrm{kPa}$ & 29 (48.3\%) \\
\hline$\geq 40 \mathrm{kPa}$ & $15(25 \%)$ \\
\hline CTP & $5(5 ; 6)$ \\
\hline $\mathrm{CTP} \geq 7$ & $6(10.3 \%)$ \\
\hline
\end{tabular}

(Continued)
TABLE 1 | Continued

\begin{tabular}{|c|c|}
\hline Characteristics & Data \\
\hline HVPG $(\mathrm{mmHg})$ & $16(11 ; 18)$ \\
\hline$<16 \mathrm{mmHg}$ & 15 (48.4\%) \\
\hline $16-20 \mathrm{mmHg}$ & $11(35.5 \%)$ \\
\hline$\geq 20 \mathrm{mmHg}$ & $5(16.1 \%)$ \\
\hline \multicolumn{2}{|l|}{ Plasma biomarkers } \\
\hline \multicolumn{2}{|c|}{ Bacterial translocation } \\
\hline LPS (EU/mL) & $0.9(0.7 ; 1.2)$ \\
\hline $\operatorname{LBP}(\mu \mathrm{g} / \mathrm{mL})$ & $1(0.6 ; 1.4)$ \\
\hline $\mathrm{sCD} 14(\mu \mathrm{g} / \mathrm{mL})$ & $2.1(1.6 ; 3.2)$ \\
\hline FABP-2 (ng/mL) & $0.4(0.1 ; 0.7)$ \\
\hline \multicolumn{2}{|l|}{ Inflammation } \\
\hline IP-10 (a.u.) & 1,221.5 (865.3; 1,799.5) \\
\hline MCP-1 (а.u.) & $493.8(276.1 ; 684.1)$ \\
\hline IL-8 (a.u.) & 117.8 (74.6; 185.8) \\
\hline $\mathbb{I L}-1 \beta$ (a.u.) & $15(13 ; 27.6)$ \\
\hline IL-18 (a.u.) & $988.5(573.1 ; 1,670.9)$ \\
\hline IL-6 (a.u.) & $65.3(33.8 ; 156.3)$ \\
\hline TNF- $\alpha$ (a.u.) & $9.8(7.4 ; 12)$ \\
\hline IL-1RA (а.u.) & $18(13 ; 25.9)$ \\
\hline sRANKL (a.u.) & $24.3(19 ; 36.4)$ \\
\hline OPG (a.u.) & $217.5(158.5 ; 307)$ \\
\hline \multicolumn{2}{|c|}{ Endothelial dysfunction } \\
\hline sVCAM-1 (a.u.) & $10,747(8,616.8 ; 12,142.3)$ \\
\hline sICAM-1 (a.u.) & $107.8(63.5 ; 163.1)$ \\
\hline TNFR-I (a.u.) & $32(20.4 ; 57.8)$ \\
\hline \multicolumn{2}{|l|}{ Coagulopathy } \\
\hline PAl-1 (a.u.) & 1,054.8 (808.6; 1,315.3) \\
\hline D-dimer (a.u.) & 1,767.5 (653.4; 4,289.9) \\
\hline \multicolumn{2}{|l|}{ Angiogenesis } \\
\hline VEGF-A (a.u.) & 76 (57.6; 90.8) \\
\hline sVEGF-R1 (a.u.) & $44.5(32.4 ; 69.5)$ \\
\hline
\end{tabular}

Statistics: Values are expressed as absolute number (percentage) and median (interquartile range).

HCV, hepatitis C virus; HIV, human immunodeficiency virus; IVDU, intravenous drug user; IFNo, interferon-alpha; DAAs, direct-acting antivirals; NRTI, nucleoside analog HIV reverse; NNRTI, non-nucleoside analog HIV reverse transcriptase inhibitor; PI, protease inhibitor; II, integrase inhibitor; AIDS, acquired immune deficiency syndrome; HCVRNA, HCV plasma viral load; LSM, liver stiffness measures; CPT, Child-Pugh-Turcotte; KVPG, hepatic venous pressure gradient ( $\mathrm{mmHg}$ ); a.u., arbitrary units of fluorescence; sCD14, soluble CD14; LPS, lipopolysaccharide; FABP2, fatty acid-binding protein 2; $L B P$, lipopolysaccharide binding protein; IL, interleukin; IL-1RA, interleukin-1 receptor antagonist; TNF- $\alpha$, tumor necrosis factor alpha; IP-10, IFN- $\gamma$-inducible protein 10; MCP1, monocyte chemoattractant protein-1; OPG, osteoprotegerin; SRANKL, soluble receptor activator of nuclear factor-kappa B ligand; sVCAM-1, soluble vascular cell adhesion molecule 1; sICAM-1, soluble intercellular cell adhesion molecule 1; sTNFR-1, soluble tumor necrosis factor receptor 1; PAI-1, plasminogen activator inhibitor-1; VEGF-A; vascular endothelial growth factor $A$; sVEGF-R1, soluble receptor 1 for vascular endothelial growth factor.

\section{Clinical Data and Samples}

Clinical data and samples were collected at the baseline (initiation of HCV treatment) and at the end of follow-up (48 weeks after completing HCV therapy). 
Epidemiological and clinical data were collected through an online form, which fulfilled the confidentiality requirements. These data were monitored to verify that all the information in the database matched the patients' records. The LSM was carried out by trained operators of transient elastography (FibroScan ${ }^{\circledR}$, Echosens, Paris, France), as we previously described (35). LSM values were reported in kilopascals $(\mathrm{kPa})$ and range from 2.5 to $75 \mathrm{kPa}$. The CTP score was calculated from five factors (total bilirubin, albumin, international normalized ratio, ascites, and encephalopathy) and range from 5 to 15 points. Hemodynamic studies were performed after overnight fasting under light sedation with intravenous midazolam, as we previously described (36). The HVPG was measured as the difference between wedged hepatic venous pressure and free hepatic venous pressure in millimeters of mercury $(\mathrm{mmHg})$.

Blood samples were collected by venipuncture in EDTA tubes, which were then sent to the HIV HGM BioBank (http:// hivhgmbiobank.com/?lang=en), where they were processed and immediately stored until use at $-80^{\circ} \mathrm{C}$.

\section{Enzyme-Linked Immunosorbent Assays}

Plasma biomarkers were measured by ProcartaPlexTM multiplex immunoassay (Bender MedSystems GmbH, Vienna, Austria) by using a Luminex $200^{\mathrm{TM}}$ analyzer (Luminex Corporation, Austin, TX, United States) according to the manufacturer's specifications. Plasma biomarkers measured were: (i) inflammation: IFN- $\gamma$-inducible protein 10 (IP-10), monocyte chemoattractant protein-1 (MCP1), interleukin (IL)-8; IL-1 $\beta$, IL-18, IL-6, tumor necrosis factor-alpha (TNF- $\alpha$ ), interleukin-1 receptor antagonist (IL-1RA), osteoprotegerin (OPG) and soluble receptor activator of nuclear factor-kappa B ligand (sRANKL); (ii) endothelial dysfunction: soluble intercellular cell adhesion molecule 1 (sICAM-1); soluble vascular cell adhesion molecule 1 (sVCAM-1), and soluble tumor necrosis factor receptor 1 (sTNFR-1); (iii) coagulopathy: plasminogen activator inhibitor-1 (PAI-1) and D-dimer; (iv) angiogenesis: soluble receptor 1 for vascular endothelial growth factor (sVEGF-R1) and vascular endothelial growth factor A (VEGF-A). Because a high proportion of the analyzed samples were below the lower limit of detection, we used the raw fluorescence intensity values in arbitrary units, without subtracting blank, as a relative quantification of the analyte abundances (37).

We also used commercial simple ELISA assays for biomarkers that were not available by multiplex ELISA: Lipopolysaccharide binding protein (LBP) (R\&D Systems, Minneapolis, MN, United States), soluble CD14 (sCD14) and fatty acid-binding protein 2 (FABP-2) (Raybiotech, Peachtree Corners, GA, United States). The lipopolysaccharide (LPS; Hycult Biotech, Uden, The Netherlands) was evaluated by a Limulus amebocyte lysate chromogenic endpoint ELISA.

\section{Statistical Analysis}

Stata 15.0 (StataCorp, College Station, TX, United States) was used to perform statistical analyses. All $p$-values were twotailed and were corrected for multiple testing by using the false discovery rate with Benjamini and Hochberg procedure ( $q$ values), separately for the baseline and end of follow-up. The statistical significance was defined as $p \leq 0.05$ or $q \leq 0.05$, as appropriate.

Generalized Linear Mixed Models (GLMM) with a gamma distribution (log-link) was used to evaluate repeated measurements. Gamma distribution in GLMM is recommended for modeling skewed continuous outcomes. The log-link was applied only to the dependent variables (y), which were the severity scores of liver cirrhosis and plasma biomarkers. These outcome variables were analyzed separately, each one of them, so there was no collinearity problem. GLMM gives us the estimation of average increase $[\Delta \mathrm{x}=$ final value $(\mathrm{x} 2) \times$ baseline value $(\mathrm{x} 1)]$ of each biomarker in each of the two times. GLMM models were also used to analyze the association between the change in plasma biomarkers $(\Delta \mathrm{x})$ and the changes in severity scores of liver disease $(\Delta y)$ during the follow-up. Due to the repeated measures design and the statistical analysis by GLMM, it was not necessary to adjust the models for covariates because each patient is their control. According to your positive or negative sign, this analysis gives us the regression coefficient $(\beta)$, which indicates the effect's size and direction.

\section{RESULTS}

\section{Baseline Characteristics}

Table 1 shows the characteristics of the $50 \mathrm{HIV} / \mathrm{HCV}$-coinfected patients with advanced HCV-related cirrhosis. All patients were on ART before starting the study, and their plasma HIV viral load was undetectable ( $<50$ copies $/ \mathrm{mL}$ ). None of the participants were actively using injection drugs.

\section{Change in Outcome Measures After Achieving SVR}

The changes in the outcome measures during the follow-up are shown in Table 2. We found significant decreases in severity scores of liver disease [LSM $(q$-value $<0.001)$, HVPG ( $q$-value $=0.011)$, and CTP $(q$-value $=0.045)]$ and plasma biomarkers [LBP $(q$-value $<0.001)$, IP-10 $(q$-value $<0.001)$, IL-8 ( $q$-value $<0.001)$, IL-18 $(q$-value $<0.001)$, IL-1RA $(q$-value $=0.013)$, OPG ( $q$-value $<0.001)$, sICAM-1 $(q$-value $<0.001)$, sVCAM$1(q$-value $<0.001)$, PAI-1 $(q$-value $=0.001)$, and VEGF-A $(q$-value $=0.006)]$.

Figure 1 shows the associations between the change in values of plasma biomarkers and severity scores of liver disease. A significant direct association between the change in LSM values and the change in values of LBP ( $q$-value $<0.001)$, IP-10 ( $q$-value $<0.001)$, MCP-1 ( $q$-value $=0.008)$, IL-8 $(q$-value $<0.001)$, IL-18 $(q$-value $<0.001)$, OPG $(q$-value $=0.004)$, sVCAM-1 $(q$-value $<$ $0.001)$, sICAM-1 $(q$-value $<0.001)$, and PAI-1 $(q$-value $=0.002)$ was found. For HVPG values, we found no significant association after the $p$-values were corrected for multiple testing. For CTP values, we found significant positive associations with IP-10 ( $q$ value $=0.010)$, IL-6 $(q$-value $=0.010)$, IL-1RA $(q$-value $=0.033)$, and sICAM-1 $(q$-value $=0.010)$. 
TABLE 2 | Change in severity scores of liver disease and plasma biomarkers during follow-up in HIV-infected patients with advanced HCV-related cirrhosis.

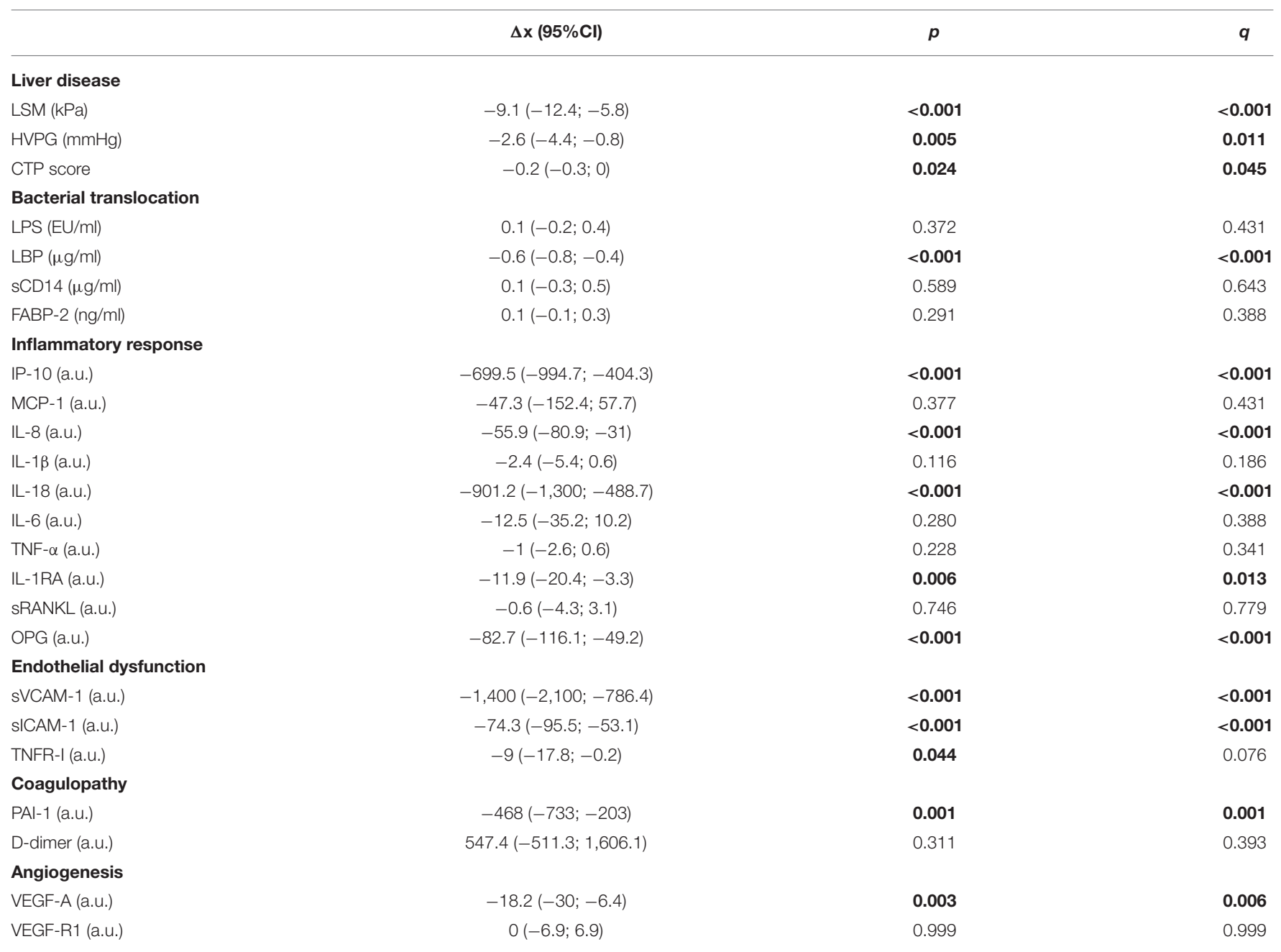

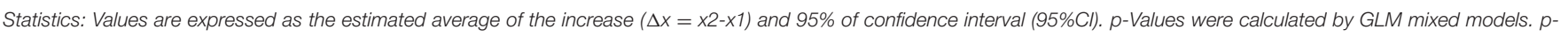

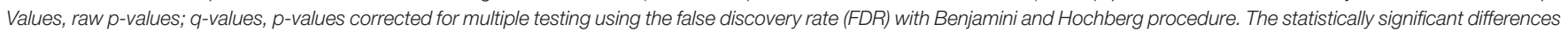
are shown in bold.

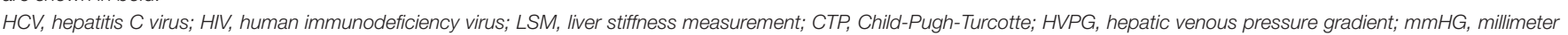

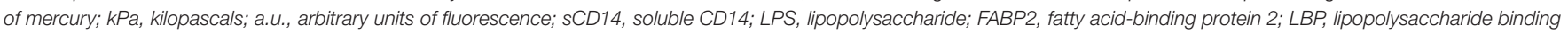

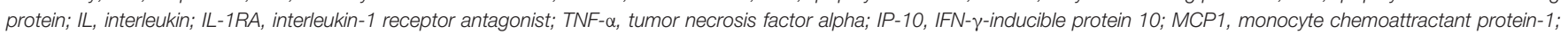

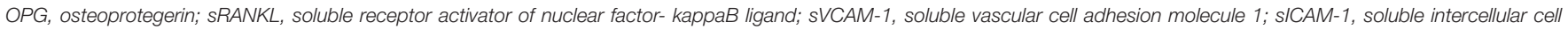

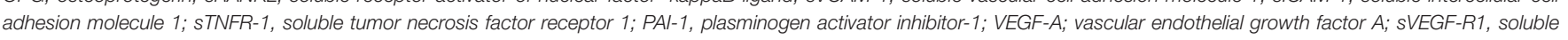
receptors for vascular endothelial growth factor.

\section{DISCUSSION}

Both HIV and HCV infection and advanced cirrhosis promote inflammation, immune activation, and dysfunction of the immune system, which are all linked to greater severity of liver disease and the development of comorbidities (1-3). Bacterial translocation in patients with advanced HCV-related cirrhosis is a crucial step in the pathogenesis of spontaneous bacterial peritonitis and bacteremia, as well as a critical factor that triggers the immune activation and inflammation, which in turn promotes hemodynamic changes and the development of decompensated cirrhosis (3). Inflammation promotes endothelial dysfunction, which is linked to the progression of $\mathrm{CHC}$ and the development of cardiovascular events (38). Moreover, hepatocytes release most of the blood's proteins, where plasma levels can be altered by $\mathrm{CHC}$ progression, promoting an increase in thrombotic risk (39). Coagulopathy has been related to a higher risk of disease progression and death in HIV-infected patients (40) and patients with advanced liver disease (41). A recent article on HIV/HCV-coinfected patients showed that plasma biomarkers of bacterial translocation, inflammation, endothelial dysfunction, and coagulopathy increased with increased liver fibrosis severity, particularly in patients with LSM $\geq 40 \mathrm{KPa}$ (35). Besides, plasma IP-10 and IL-6 have also been correlated to advanced liver disease (CTP 7-9) (42). However, the eradication of $\mathrm{HCV}$ with antiviral therapy can stop this 

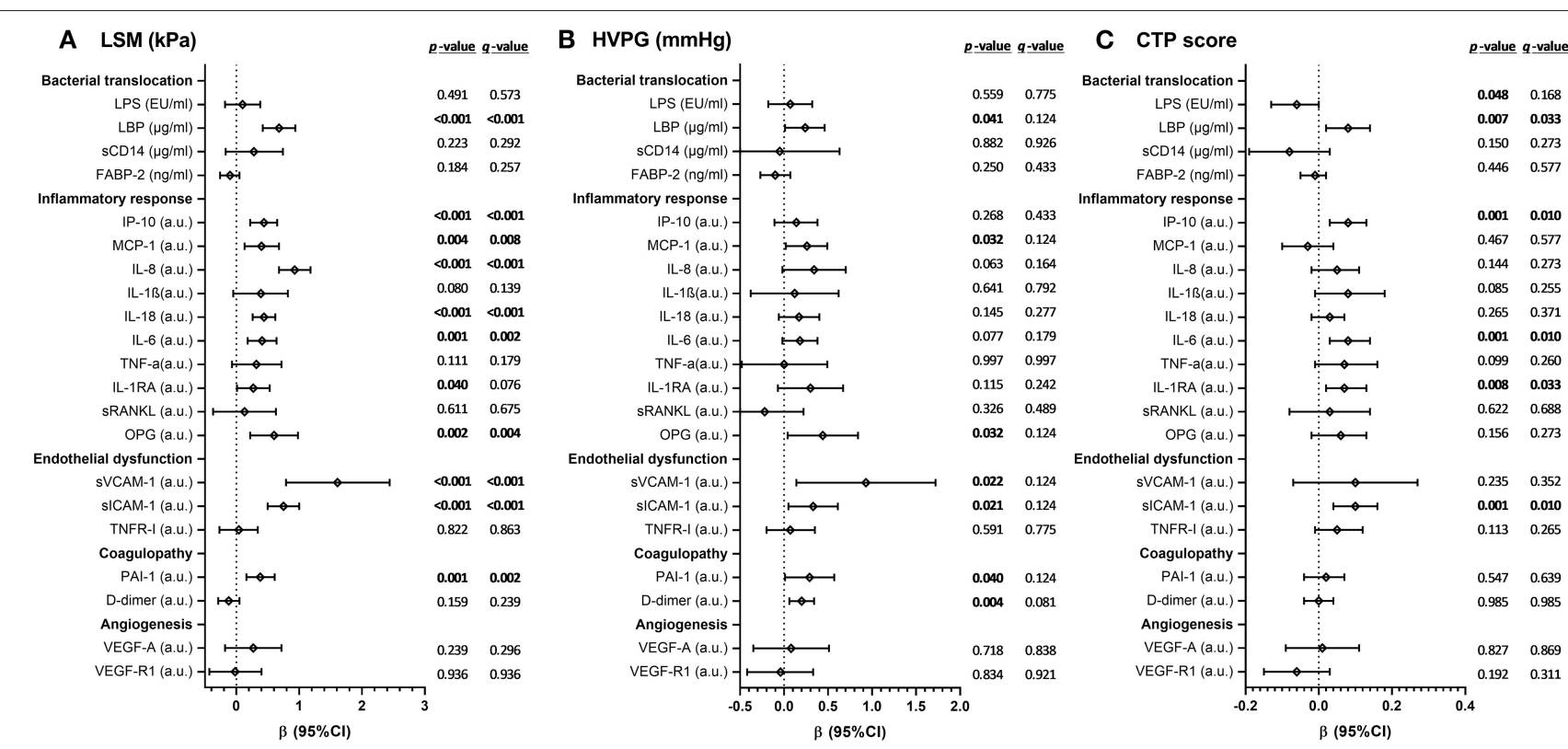

FIGURE 1 | Association between the change in values of plasma biomarkers and severity scores of liver disease [A, LSM (kPa); B, HVPG (mmHg); C, CTP score] during HCV treatment in HIV/HCV-coinfected patients with advanced cirrhosis. Statistics: Data were calculated by GLM mixed models. Values are expressed as regression coefficient $(\beta)$ and $95 \%$ of confidence interval $(95 \% \mathrm{Cl})$. $p$-Values, raw $p$-values; $q$-values, $p$-values corrected for multiple testing using the false discovery rate $(F D R)$ with Benjamini and Hochberg procedure. The statistically significant differences are shown in bold. $\mathrm{HCV}$, hepatitis $\mathrm{C}$ virus; $\mathrm{HIV}$, human immunodeficiency virus; LSM, liver stiffness measurement; CTP, Child-Pugh-Turcotte; HVPG, hepatic venous pressure gradient; mmHg, millimeter of mercury; kPa, kilopascals; a.u., arbitrary units of fluorescence; sCD14, soluble CD14; LPS, lipopolysaccharide; FABP2, fatty acid-binding protein 2; LBP, lipopolysaccharide binding protein; IL, interleukin; IL-1RA, interleukin-1 receptor antagonist; TNF- $\alpha$, tumor necrosis factor alpha; IP-10, IFN- $\gamma$-inducible protein 10; MCP1, monocyte chemoattractant protein-1; OPG, osteoprotegerin; sRANKL, soluble receptor activator of nuclear factor-kappa B ligand; sVCAM-1, soluble vascular cell adhesion molecule 1; sICAM-1, soluble intercellular cell adhesion molecule 1; sTNFR-1, soluble tumor necrosis factor receptor 1; PAI-1, plasminogen activator inhibitor-1; VEGF-A; vascular endothelial growth factor A; sVEGF-R1, soluble receptor1 for vascular endothelial growth factor.

pathological process of the liver, at least almost entirely (34). Additionally, the decrease in inflammation biomarker levels could also indicate a lower risk of developing comorbidities in cirrhotic patients who achieved SVR with DAA therapy $(1,24)$.

In our study, HCV clearance after DAA therapy promoted a significant improvement in severity scores of liver cirrhosis and many plasma biomarkers linked to inflammation (bacterial translocation, inflammatory response, and endothelial dysfunction) and coagulopathy. Our data are in concordance with many previous studies that found a significant decrease in liver disease scores of HIV/HCV-coinfected patients $(6,7,31,43-$ 45) and HCV-monoinfected patients (6-14) after HCV eradiation with DAA therapy. Besides, significant decreases have been found in plasma biomarkers of HIV/HCV-coinfected patients $(18,29-33)$ and HCV-monoinfected patients (15-20). However, there is an important lack of consistency in these previous publications regarding the plasma biomarkers and liver severity scores evaluated, time-points used to take data or samples after the end of HCV treatment, statistical analysis used, and liver fibrosis stages included.

Liver injury leads to the secretion of VEGF-A that activates quiescent HSCs into proliferative, contractile, and fibrogenic myofibroblasts (activated HSCs; aHSCs) involved in collagen deposition and development of cirrhosis (46). VEGF-A plays a crucial role in liver cancer and higher circulating VEGF-A levels correlate with tumor angiogenesis, rapid disease progression, and reduced survival (47). Besides, high VEGF-A levels are related to portal hypertension (48). Therefore, a decrease in VEGFA values indicates a good prognosis for liver disease. Previous reports did not find any change in plasma VEGF-A values after HCV eradication with DAA therapy $(43,49)$ or showed a significant increase in HCV-monoinfected patients (50). In our study, we found a reduction in plasma VEGF-A levels after HCV clearance with HCV therapy, suggesting discontinuation in the process of angiogenesis. However, this decrease in plasma VEGFA levels was not associated with changes in liver cirrhosis severity scores. In this regard, it would have been helpful to have other biomarkers of angiogenesis and fibrosis (47), such as plateletderived growth factor (PDGF), transforming growth factor- $\beta 1$ (TGF- $\beta 1$ ), and fibroblast growth factor (FGF), but these were not measured in our study.

The relationship between plasma biomarkers (bacterial translocation, inflammatory response, endothelial dysfunction, coagulopathy, and angiogenesis) and liver disease scores (LSM, HVPG, and CTP) has been scarcely explored in patients with advanced cirrhosis after HCV eradication with DAAs. Laursen et al. (20) reported that the levels of macrophage activation markers (sCD163 and soluble mannose receptor) correlated with LSM values during follow-up in HCV-monoinfected patients. Kostadinova et al. (31) showed that an improvement in LSM 
values associated with a decrease in sCD14 levels after IFNfree HCV therapy. Additionally, plasma levels of sCD163, IL6, and Mac2-binding protein correlated with AST level and APRI score changes. In our study, decreases in several plasma biomarkers levels linked to bacterial translocation, inflammatory response, endothelial dysfunction, and coagulopathy were directly associated with the reductions in liver disease scores (LSM and CTP) after HCV eradication with DAAs. Therefore, our data suggest a relation between improvement in liver cirrhosis and resolution of inflammation after HCV eradication with all-oral DAAs.

This research has several strengths and limitations that must be discussed. Firstly, the sample size was limited, which may negatively affect this study's statistical power and mask some significant values. Despite this, it should be noted that our study was multicenter, prospective, and only included patients with advanced cirrhosis. Secondly, the variation in plasma biomarkers was assessed at baseline and 48 weeks after completing HCV therapy (repeated measure design) and was analyzed by GLM mixed (each patient is your control), a statistical analysis that gives robustness to our data. Thirdly, the number of plasma biomarkers evaluated was large, and despite adjustment for multiple comparisons and the small sample size, many biomarkers were found to have significant $p$-values. Finally, the outcomes in the intermediate clinical time points, such as during DAA therapy, end of treatment (EOT), and SVR, were not collected. These intermediate time points may provide relevant information. However, we aimed to examine only the outcomes at baseline (pre-DAA therapy) and the end of follow-up (postSVR) because it was a simple design that could facilitate the achievement of our objectives.

\section{CONCLUSION}

In conclusion, the HCV eradication with all-oral DAAs in $\mathrm{HIV} / \mathrm{HCV}$-coinfected patients with advanced cirrhosis promoted an improvement in the severity of advanced cirrhosis and plasma biomarkers (inflammation, coagulopathy, and angiogenesis). The decrease in plasma biomarkers was mainly related to the reduction in LSM values.

\section{DATA AVAILABILITY STATEMENT}

The raw data supporting the conclusions of this article will be made available by the authors, without undue reservation.

\section{REFERENCES}

1. Naggie S. Hepatitis C Virus, Inflammation, and Cellular Aging: Turning Back Time. Top Antivir Med. (2017) 25:3-6.

2. Shin EC, Sung PS, Park SH. Immune responses and immunopathology in acute and chronic viral hepatitis. Nat Rev Immunol. (2016) 16:509-23. doi: 10.1038/nri.2016.69

3. Albillos A, Lario M, Alvarez-Mon M. Cirrhosis-associated immune dysfunction: distinctive features and clinical relevance. J Hepatol. (2014) 61:1385-96. doi: 10.1016/j.jhep.2014.08.010

\section{ETHICS STATEMENT}

The studies involving human participants were reviewed and approved by Ethics Committee of the Instituto de Salud Carlos III (CEI PI 41_2014). The patients/participants provided their written informed consent to participate in this study.

\section{AUTHOR CONTRIBUTIONS}

SR, JB, and JG-G: conceptualization. JB, JG-G, CD, VH, PG-B, and LI-S: data curation. LM, SS, JM, SR, and MAJ-S: formal analysis. JB, JG-G, MAJ-S, and SR: funding acquisition. LM and PG-B: investigation and methodology. JB: project administration. SR: supervision and visualization. MAJ-S and SR: writing-original draft preparation. LM and JB: writingreview and editing. All authors have read and approved the final manuscript.

\section{FUNDING}

This study was supported by grants from Instituto de Salud Carlos III (ISCII; Grant Numbers PI20/00474 and PI17/00657 to JB, PI20/00507 and PI17/00903 to JG-G, CP17CIII/00007 and PI18CIII/00028 to AJ-S, and PI20CIII/00004 and PI17CIII/00003 to SR). The study was also funded by the RD16CIII/0002/0002, RD16/0025/0017, and RD16/0025/0018 projects as part of the Plan Nacional $\mathrm{R}+\mathrm{D}+\mathrm{I}$ and cofunded by ISCIII-Subdirección General de Evaluación and the Fondo Europeo de Desarrollo Regional (FEDER). JB is an investigator from the Programa de Intensificación de la Actividad Investigadora en el Sistema Nacional de Salud (I3SNS), Refs INT16/00100.

\section{ACKNOWLEDGMENTS}

This study would not have been possible without the collaboration of all the patients, medical and nursery staff and data managers who have taken part in the project. We want to acknowledge the support of the Spanish HIV HGM BioBank for the collection of biological samples and their storage. This manuscript has been released as a pre-print at Medrano et al. (51).
4. Thrift AP, El-Serag HB, Kanwal F. Global epidemiology and burden of HCV infection and HCV-related disease. Nat Rev Gastroenterol Hepatol. (2017) 14:122-32. doi: 10.1038/nrgastro.2016.176

5. Ekpanyapong S, Reddy KR. Hepatitis C virus therapy in advanced liver disease: outcomes and challenges. United European Gastroenterol J. (2019) 7:642-50. doi: 10.1177/2050640619840149

6. Fernandes FF, Piedade J, Guimaraes L, Nunes EP, Chaves U, Goldenzon RV, et al. Effectiveness of direct-acting agents for hepatitis $\mathrm{C}$ and liver stiffness changing after sustained virological response. J Gastroenterol Hepatol. (2019) 34:2187-95. doi: 10.1111/jgh.14707 
7. Macias J, Granados R, Tellez F, Merino D, Perez M, Morano LE, et al. Similar recovery of liver function after response to all-oral HCV therapy in patients with cirrhosis with and without HIV coinfection. J Viral Hepat. (2019) 26:16-24. doi: 10.1111/jvh.12990

8. Lee YC, Hu TH, Hung $\mathrm{CH}$, Lu SN, Chen $\mathrm{CH}$, Wang JH. The change in liver stiffness, controlled attenuation parameter and fibrosis-4 index for chronic hepatitis C patients with direct-acting antivirals. PLoS ONE. (2019) 14:e0214323. doi: 10.1371/journal.pone.0214323

9. Afdhal N, Everson GT, Calleja JL, McCaughan GW, Bosch J, Brainard DM, et al. Effect of viral suppression on hepatic venous pressure gradient in hepatitis C with cirrhosis and portal hypertension. J Viral Hepat. (2017) 24:823-31. doi: 10.1111/jvh.12706

10. Lens S, Alvarado-Tapias E, Marino Z, Londono MC, E LL, Martinez J, et al. Effects of all-oral anti-viral therapy on HVPG and systemic hemodynamics in patients with hepatitis C virus-associated cirrhosis. Gastroenterology. (2017) 153:1273-83.el. doi: 10.1053/j.gastro.2017.07.016

11. Mandorfer M, Kozbial K, Schwabl P, Freissmuth C, Schwarzer R, Stern R, et al. Sustained virologic response to interferon-free therapies ameliorates HCV-induced portal hypertension. J Hepatol. (2016) 65:692-9. doi: 10.1016/j.jhep.2016.05.027

12. Gentile I, Scotto R, Coppola C, Staiano L, Amoruso DC, De Simone T, et al. Treatment with direct-acting antivirals improves the clinical outcome in patients with HCV-related decompensated cirrhosis: results from an Italian real-life cohort (Liver Network Activity-LINA cohort). Hepatol Int. (2019) 13:66-74. doi: 10.1007/s12072-018-9914-6

13. El-Sherif O, Jiang ZG, Tapper EB, Huang KC, Zhong A, Osinusi A, et al. Baseline factors associated with improvements in decompensated cirrhosis after direct-acting antiviral therapy for hepatitis $\mathrm{C}$ virus infection. Gastroenterology. (2018) 154:2111-21.e8. doi: 10.1053/j.gastro.2018. 03.022

14. McCaughan GW, Thwaites PA, Roberts SK, Strasser SI, Mitchell J, Morales B, et al. Sofosbuvir and daclatasvir therapy in patients with hepatitis C-related advanced decompensated liver disease $($ MELD $>/=15)$. Aliment Pharmacol Ther. (2018) 47:401-11. doi: 10.1111/apt.14404

15. Ponziani FR, Putignani L, Paroni Sterbini F, Petito V, Picca A, Del Chierico F, et al. Influence of hepatitis $C$ virus eradication with direct-acting antivirals on the gut microbiota in patients with cirrhosis. Aliment Pharmacol Ther. (2018) 48:1301-11. doi: 10.1111/apt.15004

16. Nien HC, Hsu SJ, Su TH, Yang PJ, Sheu JC, Wang JT, et al. High serum lipopolysaccharide-binding protein level in chronic hepatitis $\mathrm{C}$ viral infection is reduced by anti-viral treatments. PLoS ONE. (2017) 12:e0170028. doi: 10.1371/journal.pone.0170028

17. Lattanzi B, Baroncelli S, De Santis A, Galluzzo CM, Mennini G, Michelini Z, et al. Microbial translocation and $\mathrm{T}$ cell activation are modified by directacting antiviral therapy in HCV-infected patients. Aliment Pharmacol Ther. (2018) 48:1146-55. doi: 10.1111/apt.14994

18. Mascia C, Vita S, Zuccala P, Marocco R, Tieghi T, Savinelli S, et al. Changes in inflammatory biomarkers in $\mathrm{HCV}$-infected patients undergoing direct acting antiviral-containing regimens with or without interferon. PLoS ONE. (2017) 12:e0179400. doi: 10.1371/journal.pone.0179400

19. Saraiva GN, do Rosario NF, Medeiros T, Leite PEC, Lacerda GS, de Andrade TG, et al. Restoring inflammatory mediator balance after Sofosbuvir-induced viral clearance in patients with chronic hepatitis C. Mediators Inflamm. (2018) 2018:8578051. doi: 10.1155/2018/8578051

20. Laursen TL, Siggaard CB, Kazankov K, Sandahl TD, Moller HJ, Tarp B, et al. Time-dependent improvement of liver inflammation, fibrosis, and metabolic liver function after successful direct-acting antiviral therapy of chronic hepatitis C. J Viral Hepat. (2019) 27:28-35. doi: 10.1111/jvh.13204

21. Lo Re V III, Kallan MJ, Tate JP, Localio AR, Lim JK, Goetz MB, et al. Hepatic decompensation in antiretroviral-treated patients co-infected with HIV and hepatitis $\mathrm{C}$ virus compared with hepatitis $\mathrm{C}$ virus-monoinfected patients: a cohort study. Ann Intern Med. (2014) 160:369-79. doi: 10.7326/M13-1829

22. Chen JY, Feeney ER, Chung RT. HCV and HIV co-infection: mechanisms and management. Nat Rev Gastroenterol Hepatol. (2014) 11:362-71. doi: $10.1038 /$ nrgastro.2014.17

23. Abutaleb A, Sherman KE. A changing paradigm: management and treatment of the HCV/HIV-co-infected patient. Hepatol Int. (2018) 12:500-9. doi: $10.1007 /$ s12072-018-9896-4
24. Hunt PW, Lee SA, Siedner MJ. Immunologic biomarkers, morbidity, and mortality in treated HIV infection. J Infect Dis. (2016) 214(Suppl. 2):S44-50. doi: 10.1093/infdis/jiw275

25. Sikavi C, Chen PH, Lee AD, Saab EG, Choi G, Saab S. Hepatitis C and human immunodeficiency virus coinfection in the era of direct-acting antiviral agents: no longer a difficult-to-treat population. Hepatology. (2018) 67:847-57. doi: 10.1002/hep. 29642

26. Pol S, Parlati L. Treatment of hepatitis C: the use of the new pangenotypic direct-acting antivirals in "special populations". Liver Int. (2018) 38(Suppl. 1):28-33. doi: 10.1111/liv.13626

27. Berenguer J, Rodriguez E, Miralles P, Von Wichmann MA, Lopez-Aldeguer J, Mallolas J, et al. Sustained virological response to interferon plus ribavirin reduces non-liver-related mortality in patients coinfected with $\mathrm{HIV}$ and Hepatitis C virus. Clin Infect Dis. (2012) 55:728-36. doi: 10.1093/cid/cis500

28. Berenguer J, Rodriguez-Castellano E, Carrero A, Von Wichmann MA, Montero M, Galindo MJ, et al. Eradication of hepatitis C virus and nonliver-related non-acquired immune deficiency syndrome-related events in human immunodeficiency virus/hepatitis C virus coinfection. Hepatology. (2017) 66:344-56. doi: 10.1002/hep.29071

29. Carlton-Smith C, Holmes JA, Naggie S, Lidofsky A, Lauer GM, Kim AY, et al. IFN-free therapy is associated with restoration of type I IFN response in HIV1 patients with acute HCV infection who achieve SVR. J Viral Hepat. (2018) 25:465-72. doi: $10.1111 /$ jvh. 12836

30. Lopez-Cortes LF, Trujillo-Rodriguez M, Baez-Palomo A, BenmarzoukHidalgo OJ, Dominguez-Molina B, Milanes-Guisado Y, et al. Eradication of hepatitis $\mathrm{C}$ virus (HCV) reduces immune activation, microbial translocation, and the HIV DNA level in HIV/HCV-coinfected patients. J Infect Dis. (2018) 218:624-32. doi: 10.1093/infdis/jiy136

31. Kostadinova L, Shive CL, Zebrowski E, Fuller B, Rife K, Hirsch A, et al. Soluble markers of immune activation differentially normalize and selectively associate with improvement in AST, ALT, albumin, and transient elastography during IFN-free HCV therapy. Pathog Immun. (2018) 3:149-63. doi: 10.20411/pai.v3i1.242

32. Parisi SG, Andreis S, Mengoli C, Menegotto N, Cavinato S, Scaggiante R, et al. Soluble CD163 and soluble CD14 plasma levels but not cellular HIV-DNA decrease during successful interferon-free anti-HCV therapy in HIV-1-HCV co-infected patients on effective combined anti-HIV treatment. Med Microbiol Immunol. (2018) 207:183-94. doi: 10.1007/s00430-018-0538-1

33. Najafi Fard S, Schietroma I, Corano Scheri G, Giustini N, Serafino S, Cavallari EN, et al. Direct-acting antiviral therapy enhances total $\mathrm{CD} 4^{+}$ and $\mathrm{CD}^{+}$T-cells responses, but does not alter T-cells activation among $\mathrm{HCV}$ mono-infected, and HCV/HIV-1 co-infected patients. Clin Res Hepatol Gastroenterol. (2018) 42:319-29. doi: 10.1016/j.clinre.2017.11.006

34. Li H, Huang MH, Jiang JD, Peng ZG. Hepatitis C: From inflammatory pathogenesis to anti-inflammatory/hepatoprotective therapy. World $J$ Gastroenterol. (2018) 24:5297-311. doi: 10.3748/wjg.v24.i47.5297

35. Medrano LM, Garcia-Broncano P, Berenguer J, Gonzalez-Garcia J, JimenezSousa MA, Guardiola JM, et al. Elevated liver stiffness is linked to increased biomarkers of inflammation and immune activation in HIV/hepatitis C virus-coinfected patients. AIDS. (2018) 32:1095-105. doi: 10.1097/QAD.0000000000001787

36. Rincon D, Lo Iacono O, Tejedor M, Hernando A, Ripoll C, Catalina MV, et al. Prognostic value of hepatic venous pressure gradient in patients with compensated chronic hepatitis C-related cirrhosis. Scand J Gastroenterol. (2013) 48:487-95. doi: 10.3109/00365521.2012.711848

37. Breen EJ, Tan W, Khan A. The statistical value of raw fluorescence signal in Luminex xMAP based multiplex immunoassays. Sci Rep. (2016) 6:26996. doi: 10.1038/srep26996

38. Akcam FZ, Tigli A, Kaya O, Ciris M, Vural H. Cytokine levels and histopathology in chronic hepatitis B and chronic hepatitis C. J Interferon Cytokine Res. (2012) 32:570-4. doi: 10.1089/jir.2012.0048

39. Gonzalez-Reimers E, Quintero-Platt G, Martin-Gonzalez C, Perez-Hernandez O, Romero-Acevedo L, Santolaria-Fernandez F. Thrombin activation and liver inflammation in advanced hepatitis $\mathrm{C}$ virus infection. World $\mathrm{J}$ Gastroenterol. (2016) 22:4427-37. doi: 10.3748/wjg.v22.i18.4427

40. Leeansyah E, Malone DF, Anthony DD, Sandberg JK. Soluble biomarkers of HIV transmission, disease progression and comorbidities. Curr Opin HIV AIDS. (2013) 8:117-24. doi: 10.1097/COH.0b013e32835c7134 
41. Sherman KE. Advanced liver disease: what every hepatitis $C$ virus treater should know. Top Antivir Med. (2011) 19:121-5.

42. Salguero S, Medrano LM, Gonzalez-Garcia J, Berenguer J, Montes ML, Diez C, et al. Plasma IP-10 and IL-6 are linked to Child-Pugh B cirrhosis in patients with advanced HCV-related cirrhosis: a cross-sectional study. Sci Rep. (2020) 10:10384. doi: 10.1038/s41598-020-67159-3

43. Schwabl P, Mandorfer M, Steiner S, Scheiner B, Chromy D, Herac M, et al. Interferon-free regimens improve portal hypertension and histological necroinflammation in HIV/HCV patients with advanced liver disease. Aliment Pharmacol Ther. (2017) 45:139-49. doi: 10.1111/apt.13844

44. Navarro J, Laguno M, Vilchez HH, Guardiola JM, Carrion JA, Force L, et al. Efficacy and safety of direct antiviral agents in a cohort of cirrhotic HCV/HIV-coinfected patients. J Antimicrob Chemother. (2017) 72:2850-6. doi: $10.1093 / \mathrm{jac} / \mathrm{dkx} 223$

45. Lledo GM, Carrasco I, Benitez-Gutierrez LM, Arias A, Royuela A, Requena $\mathrm{S}$, et al. Regression of liver fibrosis after curing chronic hepatitis $\mathrm{C}$ with oral antivirals in patients with and without HIV coinfection. Aids. (2018) 32:2347-52. doi: 10.1097/QAD.0000000000001966

46. Tsuchida T, Friedman SL. Mechanisms of hepatic stellate cell activation. Nat Rev Gastroenterol Hepatol. (2017) 14:397-411. doi: 10.1038/nrgastro.2017.38

47. Morse MA, Sun W, Kim R, He AR, Abada PB, Mynderse M, et al. The role of angiogenesis in hepatocellular carcinoma. Clin Cancer Res. (2019) 25:912-20. doi: 10.1158/1078-0432.CCR-18-1254

48. Fernandez M. Molecular pathophysiology of portal hypertension. Hepatology. (2015) 61:1406-15. doi: 10.1002/hep.27343
49. Faillaci F, Marzi L, Critelli R, Milosa F, Schepis F, Turola E, et al. Liver angiopoietin-2 is a key predictor of de novo or recurrent hepatocellular cancer after hepatitis C virus direct-acting antivirals. Hepatology. (2018) 68:1010-24. doi: $10.1002 /$ hep. 29911

50. Villani R, Facciorusso A, Bellanti F, Tamborra R, Piscazzi A, Landriscina M, et al. DAAs rapidly reduce inflammation but increase serum VEGF level: a rationale for tumor risk during anti-HCV treatment. PLoS ONE. (2016) 11:e0167934. doi: 10.1371/journal.pone.0167934

51. Medrano LM, Berenguer J, Salguero S, González-García J, Díez C, Hontañón $\mathrm{V}$, et al. Improvement of liver disease and inflammation in patients with advanced HCV-related cirrhosis after antiviral therapy. Res Square. [Preprint]. (2020). doi: 10.21203/rs.3.rs-45478/v1

Conflict of Interest: The authors declare that the research was conducted in the absence of any commercial or financial relationships that could be construed as a potential conflict of interest.

Copyright $\odot 2021$ Medrano, Berenguer, Salgüero, González-García, Díez, Hontañón, Garcia-Broncano, Ibañez-Samaniego, Bellón, Jiménez-Sousa and Resino. This is an open-access article distributed under the terms of the Creative Commons Attribution License (CC BY). The use, distribution or reproduction in other forums is permitted, provided the original author(s) and the copyright owner(s) are credited and that the original publication in this journal is cited, in accordance with accepted academic practice. No use, distribution or reproduction is permitted which does not comply with these terms. 


\section{APPENDIX}

\section{The ESCORIAL study group}

Hospital General Universitario Gregorio Marañón (Madrid, Spain): Cristina Díez, Luis Ibáñez, Leire Pérez-Latorre, Diego Rincón, Teresa Aldámiz-Echevarría, Vega Catalina, Pilar Miralles, Teresa Aldámiz-Echevarría, Francisco Tejerina, María C Gómez-Rico, Esther Alonso, José M Bellón, Rafael Bañares, and Juan Berenguer.

Hospital Universitario La Paz/IdiPAZ (Madrid, Spain): José Arribas, José I Bernardino, Carmen Busca, Javier GarcíaSamaniego, Víctor Hontañón, Luz Martín-Carbonero, Rafael Micán, María L Montes-Ramírez, Victoria Moreno, Antonio Olveira, Ignacio Pérez-Valero, Eulalia valencia, and Juan González-García.

Hospital Universitario Puerta de Hierro (Madrid, Spain): Elba Llop and José Luis Calleja.

Hospital Universitario Ramón y Cajal (Madrid, Spain): Javier Martínez and Agustín Albillos.

Fundación SEIMC/GeSIDA (Madrid, Spain): Marta de Miguel, María Yllescas, and Herminia Esteban. 